\title{
A Comparative Approach of Tumor-Associated Inflammation in Mammary Cancer between Humans and Dogs
}

\author{
Maria Isabel Carvalho, ${ }^{1,2}$ Ricardo Silva-Carvalho, ${ }^{3}$ Isabel Pires, ${ }^{1,2}$ Justina Prada, ${ }^{1,2}$ \\ Rodolfo Bianchini, ${ }^{4}$ Erika Jensen-Jarolim, ${ }^{4,5}$ and Felisbina L. Queiroga ${ }^{2,6,7}$ \\ ${ }^{1}$ CECAV, University of Trás-os-Montes and Alto Douro, 5001-801 Vila Real, Portugal \\ ${ }^{2}$ Department of Veterinary Sciences, University of Trás-os-Montes and Alto Douro, 5001-801 Vila Real, Portugal \\ ${ }^{3}$ Centre of Biological Engineering (CEB), University of Minho, Campus de Gualtar, 4710-057 Braga, Portugal \\ ${ }^{4}$ The Interuniversity Messerli Research Institute, The University of Veterinary Medicine Vienna, \\ Medical University Vienna and University Vienna, Vienna, Austria \\ ${ }^{5}$ Institute of Pathophysiology and Allergy Research, Center for Pathophysiology, Infectiology and Immunology, \\ Medical University Vienna, Vienna, Austria \\ ${ }^{6}$ Center for the Study of Animal Sciences, CECA-ICETA, University of Porto, 4051-401 Porto, Portugal \\ ${ }^{7}$ Center for Research and Technology of Agro-Environment and Biological Sciences (CITAB), \\ University of Trás-os-Montes and Alto Douro, 5001-801 Vila Real, Portugal \\ Correspondence should be addressed to Felisbina L. Queiroga; fqueirog@utad.pt
}

Received 26 July 2016; Revised 24 October 2016; Accepted 3 November 2016

Academic Editor: Stephen H. Safe

Copyright (C) 2016 Maria Isabel Carvalho et al. This is an open access article distributed under the Creative Commons Attribution License, which permits unrestricted use, distribution, and reproduction in any medium, provided the original work is properly cited.

\begin{abstract}
Infiltrating cells of the immune system are widely accepted to be generic constituents of tumor microenvironment. It has been well established that the development of mammary cancer, both in humans and in dogs, is associated with alterations in numbers and functions of immune cells at the sites of tumor progression. These tumor infiltrating immune cells seem to exhibit exclusive phenotypic and functional characteristics and mammary cancer cells can take advantage of signaling molecules released by them. Cancer related inflammation has an important role in mammary carcinogenesis, contributing to the acquisition of core hallmark capabilities that allow cancer cells to survive, proliferate, and disseminate. Indeed, recent studies in human breast cancer and in canine mammary tumors have identified a growing list of signaling molecules released by inflammatory cells that serve as effectors of their tumor-promoting actions. These include the COX-2, the tumor EGF, the angiogenic VEGF, other proangiogenic factors, and a large variety of chemokines and cytokines that amplify the inflammatory state. This review describes the intertwined signaling pathways shared by T-lymphocytic/macrophage infiltrates and important tissue biomarkers in both human and dog mammary carcinogenesis.
\end{abstract}

\section{General Introduction}

Most of the knowledge on tumor biology is derived from human and rodent studies. However, systematic comparison to spontaneous tumors in canine cancer patients could not only contribute to the improved understanding of the disease but contribute also to "translating clinical trials from human to veterinary oncology and back" [1]. This review aimed to compare, in both species, the relevant findings on the role of the immune regulation in mammary cancer.
Tumors are recognized as organs with high complexity and infiltrating immune cells are increasingly accepted to be generic constituents of them $[2,3]$. Solid cancers often show signs of inflammation and are infiltrated by many leukocyte populations including T-lymphocytes and macrophages [4, 5]. The role of inflammation in carcinogenesis is not new. Over a century ago, a causal relationship between chronic inflammation and cancer formation was proposed taking into consideration the observations that cancers frequently develop at sites of chronic inflammation [6-8]. 


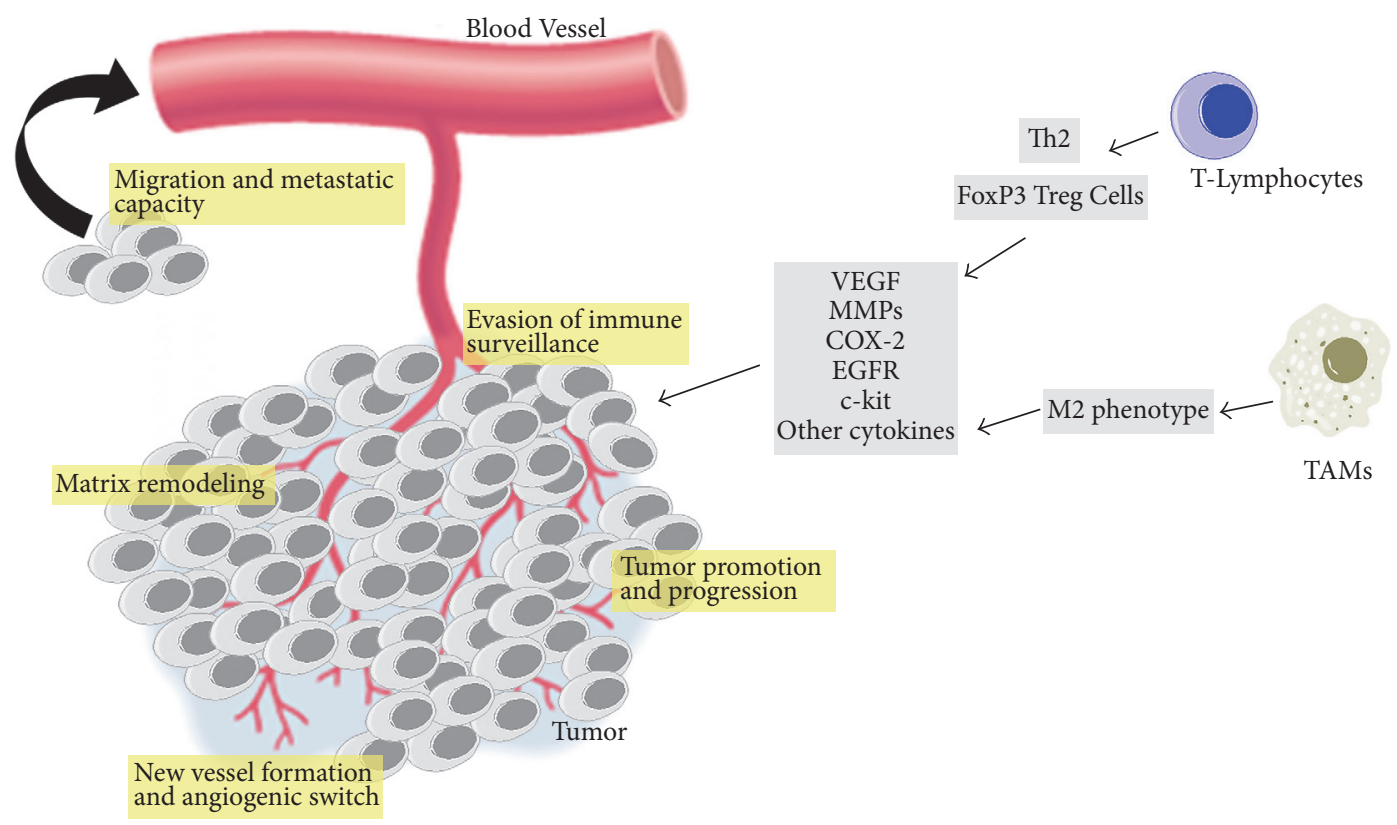

Figure 1: Cancer related inflammation has an important role in mammary carcinogenesis, contributing to tumor evasion of immune surveillance, matrix remodeling and angiogenic switch, acquisition of metastatic capacity, and tumor proliferation and progression.

Chronic inflammatory responses associated with tumor sites have a multifaceted role in carcinogenesis. Indeed, the chronic inflammation contributes to the acquisition of different hallmark capabilities by incipient neoplasms. Inflammatory cells can induce genomic instability, alterations in epigenetic events, and consequent inappropriate gene expression $[9,10]$. Furthermore, immune cells can provide bioactive molecules to the tumor microenvironment, including (i) growth factors that sustain proliferative signaling; (ii) survival factors that limit cell death; (iii) proangiogenic factors and extracellular matrix-modifying enzymes facilitating angiogenesis, invasion, and metastasis; and (iv) inductive signals that lead to activation of other hallmark-facilitating programs [10-13].

During tumor progression, changes in tumor microenvironment induce a switch in innate immune cells toward a protumorigenic function and actively contribute to immune tolerance, preventing rejection of the tumor by the immune system $[2,14]$. In this process, dendritic cells (DCs) maturation can be suppressed by changes in the cytokine balance (increased VEGF, TGF $\beta$, IL-10, IL-6, and COX- 2 and reduced IL-4, IL-12, IFN- $\alpha$, and IFN- $\gamma$ ) within the tumor, which significantly impairs the antigen presenting function of these cells [8].

Mammary cancer remains a major clinical challenge with considerable mortality both in humans and in dogs [15-18]. Over the years, research on the association between inflammation and mammary cancer pathogenesis has blossomed in both species [19-22]. Alterations of the inflammatory components within the tumor microenvironment have a significant role during carcinogenesis and recent studies have highlighted the importance of tumor-associated immune cells and their influence on neoplastic progression [17, 2326].

This review summarizes the intertwined signaling pathways shared by T-lymphocytic/macrophage infiltrates and important tissue biomarkers in both human and dog mammary carcinogenesis (all the contents are synthetized in Table 1 and illustrated in Figure 1). The inflammatory responses in mammary cancer sites are able to orchestrate hallmark-facilitating programs in the tumor microenvironment [27]. These phenomena could be important for prognosis as well as for the development of therapies aimed at redirecting the immune cell actions toward tumor destruction.

\section{Inflammatory Cells and Sustained Angiogenesis}

Similar to normal tissues, vasculature has an important role in tumor growth and progression since it provides the necessary oxygen and nutrients that are present in the blood and allows discarding the toxic waste-products of metabolism [28, 29]. The tumor vasculature, driven by angiogenesis, is thus crucial for growth and survival of tumor cells, but it may also be exploited as a target for cancer therapy [30, 31].

The association between angiogenesis and mammary tumors has been a common subject of interest in humans and dogs [32-34]. In fact, human breast cancer progression is associated with robust angiogenic activity [35]. In highly metastatic human breast cancer there is an upregulation in the expression of proangiogenic factors, such as VEGF [36]. 
TABLE 1: Relationship between T-lymphocytic and macrophages infiltrate and tissue biomarkers in human and dog mammary tumors.

\begin{tabular}{|c|c|c|}
\hline \multirow{2}{*}{ Tissue biomarkers } & \multicolumn{2}{|c|}{ T-lymphocytic and macrophages infiltrate } \\
\hline & Human breast cancer & Canine mammary tumors \\
\hline Angiogenesis & $\begin{array}{l}\text { (i) T-cells can secret VEGF [39] } \\
\text { (ii) Treg cells release TGF } \beta 1 \text { and induce VEGF expression } \\
\text { [40] } \\
\text { (iii) M2 macrophages are responsible for the production of } \\
\text { VEGF, uPA, MMP9, and CCL18 promoting tumor } \\
\text { neovascularization }[48,51]\end{array}$ & $\begin{array}{l}\text { (i) Positive correlation between } \mathrm{CD}^{+} \\
\text {T-cells, VEGF, and microvessel density [52] } \\
\text { (ii) M2 macrophages infiltration is } \\
\text { associated with VEGF expression [56] }\end{array}$ \\
\hline $\begin{array}{l}\text { Invasion and } \\
\text { metastasis }\end{array}$ & $\begin{array}{l}\text { (i) IL-10 produced by Th2-polarized CD } 4^{+} \text {T-lymphocytes } \\
\text { promotes M2-TAMs polarization, enhancing metastasis } \\
\text { through EGFR signaling activation [60] } \\
\text { (ii) IL-1 } \beta \text { elicits IL-17 expression from T-cells, resulting in } \\
\text { expansion and polarization of neutrophils that have the } \\
\text { ability to suppress cytotoxic CD } 8^{+} \text {T-lymphocytes and } \\
\text { favors metastatic spread [61] } \\
\text { (iii) MMP-2, MMP-9, and CCL18 produced by } \\
\text { macrophages increase tumor cells motility and } \\
\text { invasiveness }[62,63]\end{array}$ & $\begin{array}{l}\text { (i) } \mathrm{CD} 4^{+} \text {T-cells count and TAMs density } \\
\text { are higher in metastatic CMT; CD } 8^{+} \text {T-cells } \\
\text { count is higher in tumors without metastatic } \\
\text { behavior [64-66] }\end{array}$ \\
\hline COX-2 & $\begin{array}{l}\text { (i) COX-2-derived PGE2 enhances the production of IL-4, } \\
\text { IL-5, and IL-10 by Th2 cells and inhibits the antitumor Th1 } \\
\text { cytokines (IFN- } \gamma \text { and IL-2) }[67,68] \\
\text { (ii) PGE2 inhibits CD } 8^{+} \text {T-cells proliferation and } \\
\text { antitumor activities [69] } \\
\text { (iii) COX-2/PGE2 pathways increase tumor Treg cells } \\
\text { infiltration, differentiation, and function [70] and can } \\
\text { change the tumor-associated macrophages phenotype } \\
\text { from M1 to M2 }[71,72]\end{array}$ & $\begin{array}{l}\text { (i) Tumors with high COX-2/CD3 and high } \\
\text { COX-2/MAC are associated with tumor } \\
\text { aggressiveness and shorter OS [73] }\end{array}$ \\
\hline $\begin{array}{l}\text { Receptor tyrosine } \\
\text { kinases }\end{array}$ & $\begin{array}{l}\text { (i) T-lymphocytes and TAMs produce EGFR ligands being } \\
\text { involved in tumor progression [74-76] } \\
\text { (ii) FoxP3 }{ }^{+} \text {Treg cells express EGFR under inflammatory } \\
\text { conditions, which is related to tumor cells invasion and } \\
\text { metastasis [77] } \\
\text { (iii) c-kit dependent signaling supports an immune } \\
\text { twisting toward Th2 and Th17 subsets and the cytokines } \\
\text { produced induce T-cell tolerance, contributing to cancer } \\
\text { development [78-80] } \\
\text { (iv) c-kit inhibitors induce a reduction of TAMs and Treg } \\
\text { cell numbers and contribute to the enhancement of Th1 } \\
\text { and CD8 }{ }^{+} \text {T-cells [81-84] }\end{array}$ & $\begin{array}{l}\text { (i) Concurrent COX-2/EGFR expression is } \\
\text { associated with higher numbers of tumoral } \\
\mathrm{CD}^{+} \text {T-lymphocytes and characteristics of } \\
\text { tumor aggressiveness [19] } \\
\text { (ii) High CD3/c-kit tumors are associated } \\
\text { with variables of tumor aggressiveness and } \\
\text { shorter overall survival of animals [52] }\end{array}$ \\
\hline
\end{tabular}

Similarly, in veterinary medicine, the presence of proliferating endothelial cells and blood vessels in intratumoral and peritumoral regions of benign and malignant canine mammary tumors was shown, with the peritumoral regions having the largest blood vessel area and perimeter. Furthermore, malignant tumors have significantly more new vessels and proliferating endothelial cells compared with benign tumors and normal mammary gland tissues [32]. We have shown previously that high microvessel density in canine mammary cancer was significantly correlated with tubule formation, with the histological grade of malignancy and with clinical stage [37].

Infiltrating immune/inflammatory cells secrete a diverse repertoire of proinflammatory mediators, such as cytokines, chemokines, growth factors, and prostaglandins, which trigger the influx of even more inflammatory immune cells to the tumor microenvironment. Furthermore, some of these proinflammatory mediators directly stimulate the migration and proliferation of endothelial cells, thus promoting angiogenesis and consequently tumor growth [10, 38]. Tcells have an important role in the initiation and progression of inflammation by secreting a large number of cytokines and chemokines [39]. It was shown in in vitro studies that T-cells in inflammatory sites are in intimate contact with endothelial cells and influence angiogenesis. In fact, Tcells can secrete VEGF by specific antigens stimulation or by IL-2 and by hypoxia [39]. The human invasive breast carcinoma had a higher FoxP3 expression compared to the ductal carcinoma in situ and the adjacent normal tissues. Intratumoral levels of FoxP3, TGF $\beta 1$, and VEGF were found to be positively correlated to each other [40]. TGF $\beta 1$, by Tcell receptor (TCR) stimulation, induces FoxP3 expression in naive $\mathrm{CD} 4^{+} \mathrm{CD} 25^{-} \mathrm{FoxP}^{-}$T-cells and converts them into FoxP $^{+}$regulatory T-cells. Furthermore, Treg cells enhance 
the TGF $\beta 1$ effects thereby creating a positive autoregulatory loop of TGF $\beta 1$ signaling in $\mathrm{CD} 4^{+} \mathrm{CD} 25^{-}$T-cells that potentially stabilizes their regulatory phenotype $[41,42]$. The TGF $\beta 1$ and FoxP3 shared pathways induce an upregulated expression of VEGF which increases cancer vascularity and progression [40]. DCs are immunomodulatory cells that initiate adaptive immune responses and exert proangiogenic effects in the tumor microenvironment. Immature DCs promote angiogenesis and tumor growth, whereas mature DCs are known to suppress angiogenesis. Using a mouse model of human breast carcinoma it was observed that rapid tumor growth is associated with the infiltration of immature DCs [43]. Tumor-derived VEGF-A is the main angiogenic factor that prevents DCs maturation by inhibiting the activation of the NF- $\kappa \mathrm{B}$ via VEGFR-1 signaling [44]. Furthermore, another study reported that in human breast cancer DCs are differentiated into a phenotype that induces the expansion of Tregs by the expression of IL-10 and TGF $\beta 1$ [45], and the latter is a factor that indirectly induces the expression of VEGF [40]. Monocytes which become tumor-associated macrophages (TAMs) when entering the tumor also act as proangiogenic factor in human breast cancer [46]. In fact, the tumor microenvironment polarizes macrophages toward the M2 phenotype, which is characterized by elevated expression of potent proangiogenic factors. A transgenic mouse susceptible to mammary cancer confirmed that both the angiogenic switch and the progression to malignancy are regulated by infiltrated macrophages in the primary mammary tumors [47]. TAMs are thus responsible for the production of VEGF, of urokinase-type plasminogen activator (uPA), and of matrix metalloproteinase-9 (MMP-9) in human breast carcinomas $[46,48]$. Additionally, some studies in human breast cancer showed that the number of macrophages present in tumor sites directly correlates with increased microvessel density, tumor size, and cell proliferation $[49,50]$. Specifically, the infiltration of TAMs that express the chemokine CCL18 was positively associated with microvessel density in breast cancer. In fact, the synergistic expression of CCL18 and VEGF by the TAMs promoted endothelial cell migration and angiogenesis in this type of cancer [51].

Some studies from veterinary oncology report that in canine mammary tumors proinflammatory mediators produced by the tumor-infiltrated inflammatory cells correlate with progression and angiogenesis [20, 52-54]. In accordance, we show in dog mammary tumors a positive association between infiltrating $\mathrm{CD}^{+}{ }^{+}$T-cells, VEGF, and microvessel density, implying that $\mathrm{CD}^{+}{ }^{+}$T-lymphocyte cytokines in this type of cancer may stimulate angiogenesis through the induction of the proangiogenic VEGF. Additionally, this high CD3/VEGF expression was associated with an elevated grade of malignancy, presence of neoplastic intravascular emboli, presence of lymph node metastasis, and poor prognosis [52]. It was further shown that myeloid-derived suppressor cells (MDSCs) were significantly increased in stages III and IV dog mammary tumors and in this case MDSCs had significantly altered molecular pathways expressing amplified activation of IL-28/IL-28RA (IFN- $\gamma$ ) signaling. Moreover, IL28 secreted by the MDSCs stimulates the STAT3 pathway which increases VEGF-C expression and therefore induces angiogenesis [55]. A positive correlation between microvessel density and mast cells in malignant canine mammary cancer was found, which, in turn, suggests that these immune cells play an important role in canine mammary cancer angiogenesis, similar to human breast cancer [53]. TAMs in canine mammary cancer have already been associated, by our group, with skin ulceration, histological type, nuclear grade, tubular differentiation, and decrease in overall survival [56]. Similarly to human breast cancer, in canine mammary cancer the macrophages also polarize toward the M2 phenotype [57]. Recently, we and others demonstrated that TAM infiltration is significantly associated with VEGF expression in malignant canine mammary tumors and that genes involved in angiogenic cellular pathways have been significantly upregulated in macrophages cocultured with canine mammary tumor cell lines $[20,58]$.

\section{Inflammatory Cells, Tissue Invasion, and Metastasis}

Cancer, in its most aggressive form, is a disease characterized not only by uncontrolled cell proliferation and growth but also by uncontrolled cell migration. The activation of angiogenic vasculature is very important for cells to amplify locally (i.e., malignant transformation) and/or spread systemically (i.e., metastasize) [59]. Cancer metastasis involves a complex sequence of processes starting with local invasion, followed by entry of the cancer cells into blood or lymphatic vessels, extravasation in distant tissues, and formation of micrometastasis, followed then by progression into macroscopic tumors [29].

The cross talk between cancer cells and other cells present in the tumor microenvironment is decisive for invasive growth and metastasis. In fact, tumor invasion and metastasis can be potentiated by an inflammatory infiltrate in tumor sites [85]. In addition to promoting angiogenesis, inflammatory infiltrates promote metastatic dissemination by enhancing migratory/invasive potential of neoplastic cells through the production of tissue remodeling proteases, cytokines, and growth factors $[86,87]$. Human breast cancer development is characterized by a significant increase in lymphocytes in the neoplastic stroma [60]. For instance, Th2-polarized $\mathrm{CD} 4{ }^{+}$T-lymphocytes that express IL-4 promote invasion and subsequent metastasis of mammary adenocarcinomas by regulating the polarization and effector function of TAMs. In turn, M2-TAMs enhance metastasis through activation of EGFR signaling in human malignant mammary epithelial cells [60]. In mice bearing mammary tumors it was demonstrated that IL-1 $\beta$ elicits IL-17 expression by gamma delta Tcells, resulting in expansion and polarization of neutrophils by granulocyte colony-stimulating factor (G-CSF) action. Tumor-induced neutrophils acquire the ability to suppress cytotoxic $\mathrm{CD}^{+}$T-lymphocytes, which favors the metastatic spread [61].

Hence, even the recruitment of monocytes to the tumor has an important role. In fact, CCL2 synthesized by metastatic tumor cells is critical for recruitment of a subpopulation of CCR2 expressing monocytes that enhance the subsequent 
cell survival and extravasation through VEGF and M-CSF production [88].

Multiple studies in human cancers, including breast cancer, have reported that the presence of TAMs correlates with aggressive disease and outcome [89]. Structural changes in the extracellular matrix are necessary for cell migration. The proteolytic activities of MMP-2 and MMP-9, expressed by macrophages, promote the release of cryptic fragments by cleaving laminin-5 $\gamma 2$ chains which mimic EGF ligand and induce cell motility and invasion in EGFR overexpressing human breast carcinoma cell lines [46, 62]. The coculture with M1 and M2 macrophages increased migration of ERpositive breast cancer cell lines [90]. In a study using a mouse model for breast cancer it was demonstrated that CSF1 may promote metastatic potential by regulating the infiltration and function of TAMs [91]. In fact, using a metastatic breast cancer model it was possible to comprehend that the paracrine loop signaling between TAMs, which supply EGF, and breast cancer cells, which on the other hand supply CSF1, is sufficient for the promotion of invasion and migration $[92,93]$. CCL18 released by breast TAMs promoted the invasiveness of cancer cells by triggering integrin clustering and enhancing their adherence to the extracellular matrix [63]. Another study showed that macrophage migration inhibitory factor (MIF) also promoted tumor metastasis by increasing the prevalence of a highly immunosuppressive subpopulation of MDSCs within the tumor [94].

There are few studies in canine mammary cancer regarding the influence of immune cells in tumor invasion and metastasis $[55,64,95]$. The role of lymphocytes and macrophages in canine mammary tumor metastasis is not fully understood. When a high number of $\mathrm{CD}^{+}{ }^{+} \mathrm{T}$-cells were found in metastatic canine mammary cancer the authors suggested the involvement of this lymphocyte subtype in tumor metastasis [96]. Contrary to this study, another group showed that the relative percentage of $\mathrm{CD}^{+}$T-cells was higher in canine mammary tumors that metastasized, whereas $\mathrm{CD}^{+}{ }^{+} \mathrm{T}$-cells percentage was higher in tumors that did not metastasize $[65,66]$. In terms of TAMs, their density was significantly higher in canine mammary adenocarcinomas that metastasized [64]. Furthermore, a microarray analysis to determine the global gene expression of a coculture of canine macrophages and canine mammary cancer cells showed an upregulation of genes involved in angiogenesis in TAMs and an increase in the migratory and invasive capabilities of cancer cells [95]. Mucha et al. showed, for the first time, that MDSCs demonstrated increased activation of IL28/IL-28RA (IFN- $\gamma$ ) signaling, which stimulates STAT3 in canine mammary tumor cells therefore promoting epithelialmesenchymal transition (EMT) and increased invasion and migration [55].

\section{Inflammatory Cells and Cancer Cell Biomarkers}

4.1. Inflammatory Infiltrates and Tumor COX-2 Expression. Cyclooxygenase (COX) is the enzyme responsible for the biosynthesis of various prostanoids (lipid mediators that have several biological functions) by the conversion of arachidonic acid released from the phospholipid membrane through the action of cytosolic phospholipase A2 [97].

Human and laboratory animal studies report COX2 upregulation in mammary cancer [98-101] and several lines of evidence now strongly support that this enzyme, during mammary tumorigenesis, mediates tumor survival by several mechanisms: (i) inhibiting the tumor cell apoptosis and inducing tumor cell proliferation; (ii) increasing tumor progression by altering cells morphology; (iii) increasing cell motility and migration; (iv) sustaining proliferative signaling; (v) inducing the production of metastasis-promoting MMPs; and (vi) stimulating the tumor angiogenic switch $[102,103]$.

The COX-2-derived products, mostly prostaglandin (PG) E2 (thought to be the main tumorigenic COX-2-derived product), are known to act not only in classical cancer signaling pathways to promote carcinogenesis in primary tumor cells but also in the tumor microenvironment which contains multiple resident and infiltrating cells (including immune cells) as well as the growth factors and cytokines released by them $[29,67]$. Recent findings revealed that COX2-produced prostaglandins are potent lipid molecules that act as immunomodulators in key aspects of mammary tumor immunity [68, 104-106].

In human breast cancer COX-2-derived PGE2 has the ability to influence local immune responses in the tumor stroma contributing to tumor evasion of immune surveillance and supporting tumor development and metastasis $[102,106]$. PGE2 has diverse effects on the regulation and activity of T-cells [106, 107]. Recently, PGE2 has been implicated in the enhancement of protumorigenic Th2-type cytokine, such as IL-4, IL-5, and IL-10, and inhibition of the anti-tumor Thl cytokine production, such as IFN- $\gamma$ and IL-2 [67, 68]. Receptors EP1-4, associated with different intracellular signaling pathways, are responsible for mediating the cellular effects of PGE2 [70]. The inhibition of the Th1 cell proliferation is dependent on EP2 [108]. The EP2 and perhaps the EP4 receptors mediate the suppressive effects of PGE2 on T-cells [109]. The induction of the Th2 response by PGE2 is modulated most probably by the secondmessenger cyclic adenosine monophosphate (cAMP), since the biological products that increase the level of cAMP mimic the effects of PGE2 [110, 111].

Even though there is limited knowledge regarding the effects of PGE2 on $\mathrm{CD}^{+}$cytotoxic T-cells, it has been shown that, as for Th1 cells, PGE2 can inhibit $\mathrm{CD}^{+}$T-cell proliferation, suppress cytotoxic $\mathrm{CD}^{+} \mathrm{T}$-cell actions against the tumor, and, in terms of regulating cytokine production, decrease the production of IFN- $\gamma$ by $\mathrm{CD}^{+}$T-cell clones through a cAMP-dependent pathway [69]. Additionally, the PGE2 effects during the priming of DCs with tumor antigens inhibit completely the DCs ability to produce IL-12 and prompt the production of high levels of IL-10 [112]. In this process the PGE2-primed DCs induce the direct differentiation of naive T-cells into Th2 cells, which further supports the role of COX-2-derived PGE2 in biasing the immune system toward Th2 and away from potentially beneficial Th1 responses in tumor sites $[112,113]$. 
COX-2 has some effects on FoxP3 expression and Treg cell functions. Several studies have demonstrated that Treg cells contribute to immunosuppression in cancer and inhibit effector T-cells in a COX-2-dependent manner in mouse models or in human peripheral blood [114-117]. An intratumoral increase in COX-2 and PGE2 levels is strongly correlated with the upregulation of FoxP3 and the suppressive capabilities of Tregs in several human cancers $[118,119]$. In human breast cancer, COX-2-derived PGE2, acting through EP2 and EP4, increases Treg infiltration, differentiation, and function, which in turn suppress the maturation of other Tcells leading to immunosuppression and increased tumor cell survival [70].

Evidences from clinical and experimental studies indicate that macrophages are versatile cells that are capable of displaying different functional activities in order to promote breast cancer progression and metastasis $[20,120,121]$. TAMs polarization in mammary tumor sites are modulated by the tumor microenvironment and these cells are "educated" adopting a role that facilitates angiogenesis, matrix breakdown, and tumor cell motility in a COX-2-dependent manner $[71,105]$.

A substantial body of work indicates the immune suppressive role of COX-2 and describes the COX2/PGE2 modulation of macrophages, including the downregulation of M1 macrophage markers/cytokines, which elicit Th1 immune responses, and the upregulation of M2 macrophage markers/cytokines, which block Th1 immune responses [71, 72]. Moreover, in the murine breast cancer model, the selective COX-2 inhibitors can change the tumor-associated macrophage phenotype from M2 to M1 [105].

Considering COX-2/PGE2-mediated immunomodulation in human breast cancer, it is worth noting that the immunosuppressive cell subtypes, modulated by COX-2 pathways, share common cytokine mediators and, more importantly, each cell subtype can also generate PGE2 providing an autocrine mechanism for prolonging and enhancing their own immunosuppressive phenotype [122]. This emphasizes the importance of exploring the tumor microenvironment as a whole, rather than focusing on alterations in an individual subset of tumor-associated cells [29]. Collectively, these findings show that COX-2 and immune cells share common signaling pathways in mammary carcinogenesis, which are associated with changes in immune cell profiles and functionality and the role of COX-2 may allow neoplastic cells to evade attack by the immune system.

In canine mammary tumors there are only a limited number of studies focusing on the cross talk between COX-2, cancer cells, and immune cells $[19,73]$ and this topic is incompletely understood. Our team demonstrated a significant association of high COX-2 immunoexpression with $\mathrm{CD}^{+}{ }^{+}$lymphocytes [19] and MAC387 macrophages [73]. Tumors with concurrent high COX-2/CD3 and high COX-2/MAC were statistically associated with variables of tumor aggressiveness (high histological grade of malignancy, presence of neoplastic intravascular emboli, and presence of lymph node metastasis) and shorter overall survival of animals [73]. These findings suggest that, similarly to human breast cancer,
T-lymphocytes, macrophages, and COX-2 share functions in canine mammary carcinogenesis.

4.2. Inflammatory Infiltrates and Receptor Tyrosine Kinases (RTKs). Receptor tyrosine kinases (RTKs) are cellular proteins that have been intensively studied $[52,74,75,123]$. Their role in the control of cellular growth and differentiation is central to all organisms and has been found to participate in human and animal neoplastic diseases [124-126].

There are several mechanisms by which tyrosine kinases might acquire transforming functions. RTKs are essential components of cellular signaling pathways that are active during embryonic development and adult homeostasis [127]. Due to their roles as growth factor receptors, many RTKs have been implicated in the onset or progression of various cancers, including mammary cancer, either through receptor gain-of function mutations in the corresponding genes or through receptor/ligand overexpression by autocrineparacrine growth factor loops [128, 129].

The RTKs family include the human epidermal growth factor receptor (EGFR) family with its members HER1/EGFR and HER-2, HER-3, and HER-4; platelet-derived growth factor receptors (PDGFR, which include c-kit); fibroblast growth factor receptors (FGFRs); VEGF; hepatocyte growth factor/scatter factor receptor (HGF/SFR); ephrin receptors (Ephs); and the insulin receptor [128, 130, 131].

Here, we will only focus on the most important RTKs in mammary carcinogenesis, the EGFR and c-kit which are often overexpressed or mutated in this type of tumor $[52,126$, 132, 133], since VEGF is already described above.

In human breast cancer, RTK signaling has been described as being implicated in differentiation and migration of immune cells into tumor sites contributing to the immune balance from activation to tolerance which is implicated in tumor progression $[75,78,134,135]$. Consequently, a number of tyrosine kinase inhibitors (TKIs) have been developed which, besides direct anticancer effects, also increase the number and function of effector immune elements, while decreasing the amount and function of suppressor immune cells $[81,136]$.

Studies in preclinical breast cancer mouse models demonstrated that trastuzumab (monoclonal antibody against HER2) and cetuximab (monoclonal antibody to EGFR/HER-1) both have an important role in tumoral innate and adaptive immunity, inducing natural killer (NK) cells and cytotoxic as well as Th1 T-lymphocytes activity [137-140].

The great homology in the EGFR family among humans and dogs [126] prompted us recently to produce a recombinant canine anti-EGFR antibody for canine mammary tumor treatment [125].

Several lines of evidence suggest that ligands to EGFR family molecules (except HER-2) can be produced by nontumor cell types. The infiltrating T-lymphocytes in human breast cancer can produce EGF [76] and analysis of breast tumor explants revealed that EGF is also produced by TAMs $[74,75,141]$. In fact, the important role of macrophagesecreted EGFR ligands in malignant mammary tumor progression leads to increased carcinoma cell invasion and metastasis [75]. 
Interestingly, one study showed that even FoxP3 ${ }^{+}$Treg cells express EGFR under inflammatory conditions. The stimulation with the EGF-like growth factor amphiregulin markedly contributes to the enhancement of Treg cell functions in vitro and in a tumor vaccination model [77].

In canine mammary cancer there is only one study suggesting that concurrent COX-2/EGFR positive immunoexpression is associated with higher number of intratumoral $\mathrm{CD}^{+}$T-lymphocytes. In this work, tumoral $\mathrm{CD}^{+} \mathrm{T}$ lymphocytes may be influenced by inappropriate expression of COX-2/EGFR. COX-2 overregulation and the resulting increase in PGE2 levels induced overexpression of EGFR pathways and may represent a strategy adopted by tumors that contributes to the evasion of tumor-specific immune response [19].

In several human tumors, including breast cancer, the stem cell factor (SCF) that triggers the c-kit signaling pathways has been described as possibly being involved in the complex relationship between immune cells and tumor cells in the tumor microenvironment $[78,134]$. c-kit upregulation, on DCs, induces the activation of several signaling pathways that block IL-12 and promote IL-6 production. c-kit dependent signaling supports an immune twisting toward Th2 and Th17 subsets and away from Th1 responses. The cytokines produced induce T-cell tolerance and contribute to cancer development [78-80].

Sunitinib and sorafenib, multikinase inhibitors that block, among others, the VEGF and c-kit receptors [81], have the ability to modify the mammary tumor microenvironment in multiple ways, including the alteration of immune cell infiltration by immune subset conditioning [142]. These TKIs may contribute to the enhancement of Th1 and $\mathrm{CD}^{+} \mathrm{T}$ cells intratumoral infiltration with cytolytic activity against the tumor $[81,82]$. Sunitinib could also block the conversion of conventional $\mathrm{CD}^{+}{ }^{+} \mathrm{FoxP}^{-}$T-cells into $\mathrm{CD}^{+}{ }^{+} \mathrm{FoxP}^{+}{ }^{+}$Treg cells [81]. Studies in vitro and using tumor-bearing mice showed that c-kit inhibitors may induce a reduction of Treg cell number, decreasing consequently the expression of immunosuppressive cytokines (IL-10, TGF $\beta$ ) [83]. Furthermore, in mice, sunitinib prompted antiangiogenic effects and promoted direct proapoptotic properties, resulting in a decline of mammary tumor progression. Regarding TAMs, their density was slightly reduced under sunitinib treatment [84].

Canine mammary tumor studies on the interplay between c-kit and tumor immunology are scarce. However, one study demonstrated a positive correlation between $\mathrm{CD}^{+}$ T-lymphocytes and c-kit immunoexpression. Tumors with high CD3/c-kit were associated with tumor aggressiveness (high histological grade of malignancy, presence of neoplastic intravascular emboli, and presence of lymph node metastases) and shorter overall survival of animals. The results of this work are a first attempt to explore the possible common signaling pathways between c-kit and immune system in canine mammary carcinogenesis [52].

Therefore, the findings described above prove that RTK pathways not only are important for the remodeling of mammary tumor microenvironment but also could be a very important target for tumor immunological therapy [135].

\section{Concluding Remarks}

Cancer can take advantage of the stromal inflammation [143]. T-lymphocytes, macrophages, and other inflammatory cells in human and the dog mammary tumor microenvironment acquired protumorigenic properties that are crucial to fuel the major biological processes involved in tumor development, progression, and metastasis $[14,46,143,144]$.

The involvement of inflammatory cells in tumor hallmark acquisitions by supplying proangiogenic growth factors, cytokines, and proteases and the recent success of checkpoint inhibitors in clinical oncology approve the great relevance of the dark side of immune regulation for driving cancer.

The similarities described above between humans and dogs prove the value of dog as an important translational model for comparative oncology in the study of the molecular signaling based on tumor immunosuppression. In the future continuing research on this topic seems to be relevant in order to find novel immunotherapies that may target tumor microenvironment interconnected pathways.

\section{Abbreviations}

cAMP: Cyclic adenosine monophosphate

CCL: $\quad$ Chemokine (C-C motif) ligand

CCR: $\quad \mathrm{C}-\mathrm{C}$ chemokine receptor

COX: Cyclooxygenase

CSF1: Macrophage colony-stimulating factor 1

DCs: Dendritic cells

EGF: Epidermal growth factor

EGFR: Epidermal growth factor receptor (ErbB1 or HER-1)

EMT: Epithelial-to-mesenchymal transition

Ephs: Ephrin receptors

ER: $\quad$ Estrogen receptor

FGF: Fibroblast growth factor

FoxP3: Forkhead box P3

G-CSF: Granulocyte colony-stimulating factor

HER-2: Human epidermal growth factor receptor 2 (ErbB2)

HGF/SFR: Hepatocyte growth factor/scatter factor receptor

IL: $\quad$ Interleukin

IFN- $\lambda$ : Interferon gamma

M-CSF: Macrophage colony-stimulating factor

MDSCs: Myeloid-derived suppressor cells

MIF: $\quad$ Macrophage migration inhibitory factor

MMP: $\quad$ Matrix metalloproteinase

$\mathrm{NF} \kappa \mathrm{B}: \quad$ Nuclear factor kappa-B

NK: $\quad$ Natural killer

PDGF: Platelet-derived growth factor

PGE2: Prostaglandin E2

RTKs: $\quad$ Receptor tyrosine kinases

SCF: $\quad$ Stem cell factor

STAT3: $\quad$ Signal transducer and activator of transcription 3

TAMs: Tumor-associated macrophages

TCR: $\quad$ T-cell receptor

TGF $\beta$ : Transforming growth factor beta 
TGF $\beta$ R: Transforming growth factor beta receptor

TKIs: Tyrosine kinase inhibitors

Treg: Regulatory T-lymphocyte

uPA: Urokinase-type plasminogen activator

VEGF: Vascular endothelial growth factor

VEGFR: Vascular endothelial growth factor receptor.

\section{Competing Interests}

The authors declare that they have no conflict of interests concerning the contents of this article.

\section{Acknowledgments}

The work was supported partially by the Strategic Research Project Pest OE/AGR/UI0772/2011 and the Research Project UID/AGR/04033/2013, by a Ph.D. scholarship SFRH/BD/ $78771 / 2011$ financed by the Portuguese Foundation for Science and Technology (FCT), and in part by the Austrian Science Fund (FWF), SFB F4606-B28, to Erika JensenJarolim.

\section{References}

[1] I. Fürdös, J. Fazekas, J. Singer, and E. Jensen-Jarolim, “Translating clinical trials from human to veterinary oncology and back," Journal of Translational Medicine, vol. 13, no. 1, article no. 265, 2015.

[2] B. B. Aggarwal, "Inflammation, a silent killer in cancer is not so silent!" Current Opinion in Pharmacology, vol. 9, no. 4, pp. 347-350, 2009.

[3] O. J. Finn, "Immuno-oncology: understanding the function and dysfunction of the immune system in cancer," Annals of Oncology, vol. 23, supplement 8, pp. viii6-viii9, 2012.

[4] J. W. Pollard, "Tumour-educated macrophages promote tumour progression and metastasis," Nature Reviews Cancer, vol. 4, no. 1, pp. 71-78, 2004.

[5] D. Mougiakakos, A. Choudhury, A. Lladser, R. Kiessling, and C. C. Johansson, "Regulatory T cells in cancer," Advances in Cancer Research, vol. 107, pp. 57-117, 2010.

[6] G. Sethi, M. K. Shanmugam, L. Ramachandran, A. P. Kumar, and V. Tergaonkar, "Multifaceted link between cancer and inflammation," Bioscience Reports, vol. 32, no. 1, pp. 1-15, 2012.

[7] S. Demaria, E. Pikarsky, M. Karin et al., "Cancer and inflammation: promise for biologic therapy," Journal of Immunotherapy, vol. 33, no. 4, pp. 335-351, 2010.

[8] J. A. Joyce, "Therapeutic targeting of the tumor microenvironment," Cancer Cell, vol. 7, no. 6, pp. 513-520, 2005.

[9] F. Colotta, P. Allavena, A. Sica, C. Garlanda, and A. Mantovani, "Cancer-related inflammation, the seventh hallmark of cancer: links to genetic instability," Carcinogenesis, vol. 30, no. 7, pp. 1073-1081, 2009.

[10] J. K. Kundu and Y.-J. Surh, "Inflammation: gearing the journey to cancer," Mutation Research/Reviews in Mutation Research, vol. 659, no. 1-2, pp. 15-30, 2008.

[11] D. G. DeNardo, P. Andreu, and L. M. Coussens, "Interactions between lymphocytes and myeloid cells regulate pro-versus anti-tumor immunity," Cancer and Metastasis Reviews, vol. 29, no. 2, pp. 309-316, 2010.
[12] K. E. de Visser and L. M. Coussens, "The inflammatory tumor microenvironment and its impact on cancer development," Contributions to microbiology., vol. 13, pp. 118-137, 2006.

[13] F. Balkwill and A. Mantovani, "Inflammation and cancer: back to Virchow?" The Lancet, vol. 357, no. 9255, pp. 539-545, 2001.

[14] M. I. Carvalho, I. Pires, J. Prada, and F. L. Queiroga, “A role for T-lymphocytes in human breast cancer and in canine mammary tumors," BioMed Research International, vol. 2014, Article ID 130894, 11 pages, 2014.

[15] K. Sorenmo, "Canine mammary gland tumors," Veterinary Clinics of North America-Small Animal Practice, vol. 33, no. 3, pp. 573-596, 2003.

[16] A. Ben-Baruch, "Breast cancer progression: a 'vicious cycle' of pro-malignancy activities is mediated by inflammatory cells, chemokines and cytokines," in Integration/Interaction of Oncologic Growth, G. G. Meadows, Ed., pp. 189-217, Springer, Dordrecht, The Netherlands, 2005.

[17] R. Matkowski, I. Gisterek, A. Halon et al., "The prognostic role of tumor-infiltrating CD4 and CD8 T lymphocytes in breast cancer," Anticancer Research, vol. 29, no. 7, pp. 2445-2451, 2009.

[18] M. I. Carvalho, I. Pires, J. Prada, and F. L. Queiroga, “Tlymphocytic infiltrate in canine mammary tumours: clinic and prognostic implications," In Vivo, vol. 25, no. 6, pp. 963-969, 2011.

[19] M. I. Carvalho, I. Pires, J. Prada, A. F. Ferreira, and F. L. Queiroga, "Positive interplay between CD3+ T-lymphocytes and concurrent COX-2/EGFR expression in canine malignant mammary tumors," Anticancer Research, vol. 35, no. 5, pp. 29152920, 2015.

[20] T. P. Raposo, I. Pires, M. I. Carvalho, J. Prada, D. J. Argyle, and F. L. Queiroga, "Tumour-associated macrophages are associated with vascular endothelial growth factor expression in canine mammary tumours," Veterinary and Comparative Oncology, vol. 13, no. 4, pp. 464-474, 2015.

[21] J. H. Kim, S. K. Chon, K. S. Im, N. H. Kim, K. W. Cho, and J. H. Sur, "Infiltrating Foxp3+ Regulatory T cells and histopathological features in canine classical and spermatocytic seminomas," Reproduction in Domestic Animals, vol. 48, no. 2, pp. 218-222, 2013.

[22] F. Liu, R. Lang, J. Zhao et al., "CD8 ${ }^{+}$cytotoxic T cell and FOXP3 ${ }^{+}$ regulatory $\mathrm{T}$ cell infiltration in relation to breast cancer survival and molecular subtypes," Breast Cancer Research and Treatment, vol. 130, no. 2, pp. 645-655, 2011.

[23] A. Merlo, P. Casalini, M. L. Carcangiu et al., "FOXP3 expression and overall survival in breast cancer," Journal of Clinical Oncology, vol. 27, no. 11, pp. 1746-1752, 2009.

[24] S. Y. Oh, H. H. Ryu, D. Y. Yoo, I. K. Hwang, O. K. Kweon, and W. H. Kim, "Evaluation of FOXP3 expression in canine mammary gland tumours," Veterinary and Comparative Oncology, vol. 12, no. 1, pp. 20-28, 2014.

[25] D. G. DeNardo and L. M. Coussens, "Inflammation and breast cancer. Balancing immune response: crosstalk between adaptive and innate immune cells during breast cancer progression," Breast Cancer Research, vol. 9, no. 4, article no. 212, 2007.

[26] G. Curigliano, "Immunity and autoimmunity: revising the concepts of response to breast cancer," Breast, vol. 20, supplement 3, pp. S71-S74, 2011.

[27] A. Ben-Baruch, "Host microenvironment in breast cancer development. Inflammatory cells, cytokines and chemokines in breast cancer progression: Reciprocal tumormicroenvironment interactions," Breast Cancer Research, vol. 5, 2003. 
[28] C. Benazzi, A. Al-Dissi, C. H. Chau et al., "Angiogenesis in spontaneous tumors and implications for comparative tumor biology," The Scientific World Journal, vol. 2014, Article ID 919570, 16 pages, 2014.

[29] D. Hanahan and R. A. Weinberg, "Hallmarks of cancer: the next generation," Cell, vol. 144, no. 5, pp. 646-674, 2011.

[30] J. Folkman, "Tumor angiogenesis: therapeutic implications," The New England Journal of Medicine, vol. 285, no. 21, pp. 11821186, 1971.

[31] J. Folkman, E. Merler, C. Abernathy, and G. Williams, "Isolation of a tumor factor responsible for angiogenesis," Journal of Experimental Medicine, vol. 133, no. 2, pp. 275-288, 1971.

[32] N. Sleeckx, L. Van Brantegem, G. Van den Eynden et al., "Angiogenesis in canine mammary tumours: a morphometric and prognostic study," Journal of Comparative Pathology, vol. 150, no. 2-3, pp. 175-183, 2014.

[33] J. Zhang, C. Liu, W. Shi et al., "The novel VEGF receptor 2 inhibitor YLL545 inhibits angiogenesis and growth in breast cancer," Oncotarget, vol. 7, no. 27, pp. 41067-41080, 2016.

[34] H. A. Vieira-Monteiro, D. R. Freitas-Alves, M. Sobral-Leite et al., "Prognostic evaluation of VEGFA genotypes and haplotypes in a cohort of Brazilian women with non metastatic breast cancer," Cancer Biology \& Therapy, vol. 17, no. 6, pp. 674-683, 2016.

[35] A. Longatto Filho, J. M. Lopes, and F. C. Schmitt, "Angiogenesis and breast cancer," Journal of Oncology, vol. 2010, Article ID 576384, 7 pages, 2010.

[36] D. G. DeNardo, M. Johansson, and L. M. Coussens, "Immune cells as mediators of solid tumor metastasis," Cancer and Metastasis Reviews, vol. 27, no. 1, pp. 11-18, 2008.

[37] M. I. Carvalho, M. J. Guimarães, I. Pires et al., "EGFR and microvessel density in canine malignant mammary tumours," Research in Veterinary Science, vol. 95, no. 3, pp. 1094-1099, 2013.

[38] J. L. Yu and J. W. Rak, "Host microenvironment in breast cancer development: inflammatory and immune cells in tumour angiogenesis and arteriogenesis," Breast Cancer Research, vol. 5, no. 2, pp. 83-88, 2003.

[39] F. Mor, F. J. Quintana, and I. R. Cohen, "Angiogenesisinflammation cross-talk: vascular endothelial growth factor is secreted by activated T cells and induces Th1 polarization," Journal of Immunology, vol. 172, no. 7, pp. 4618-4623, 2004.

[40] S. Gupta, K. Joshi, J. D. Wig, and S. K. Arora, "Intratumoral FOXP3 expression in infiltrating breast carcinoma: its association with clinicopathologic parameters and angiogenesis," Acta Oncologica, vol. 46, no. 6, pp. 792-797, 2007.

[41] W. Chen and J. E. Konkel, "TGF- $\beta$ and 'Adaptive' Foxp3 ${ }^{+}$ Regulatory T cells," Journal of Molecular Cell Biology, vol. 2, no. 1, pp. 30-36, 2010.

[42] M. C. Fantini, C. Becker, G. Monteleone, F. Pallone, P. R. Galle, and M. F. Neurath, "Cutting edge: TGF- $\beta$ induces a regulatory phenotype in $\mathrm{CD} 4{ }^{+} \mathrm{CD} 25^{-}$T cells through Foxp 3 induction and down-regulation of Smad7," Journal of Immunology, vol. 172, no. 9, pp. 5149-5153, 2004.

[43] O. Fainaru, N. Almog, C. W. Yung et al., "Tumor growth and angiogenesis are dependent on the presence of immature dendritic cells," FASEB Journal, vol. 24, no. 5, pp. 1411-1418, 2010.

[44] M. M. Dikov, J. E. Ohm, N. Ray et al., "Differential roles of vascular endothelial growth factor receptors 1 and 2 in dendritic cell differentiation," The Journal of Immunology, vol. 174, no. 1, pp. 215-222, 2005.
[45] C. Aspord, A. Pedroza-Gonzalez, M. Gallegos et al., "Breast cancer instructs dendritic cells to prime interleukin 13-secreting CD4+ $\mathrm{T}$ cells that facilitate tumor development," Journal of Experimental Medicine, vol. 204, no. 5, pp. 1037-1047, 2007.

[46] E. Obeid, R. Nanda, Y.-X. Fu, and O. I. Olopade, "The role of tumor-associated macrophages in breast cancer progression (review)," International Journal of Oncology, vol. 43, no. 1, pp. 5-12, 2013.

[47] E. Y. Lin, J.-F. Li, L. Gnatovskiy et al., "Macrophages regulate the angiogenic switch in a mouse model of breast cancer," Cancer Research, vol. 66, no. 23, pp. 11238-11246, 2006.

[48] E. Y. Lin and J. W. Pollard, "Tumor-associated macrophages press the angiogenic switch in breast cancer," Cancer Research, vol. 67, no. 11, pp. 5064-5066, 2007.

[49] F. Bolat, F. Kayaselcuk, T. Z. Nursal, M. C. Yagmurdur, N. Bal, and B. Demirhan, "Microvessel density, VEGF expression, and tumor-associated macrophages in breast tumors: correlations with prognostic parameters," Journal of Experimental \& Clinical Cancer Research, vol. 25, no. 3, pp. 365-372, 2006.

[50] S. Tsutsui, K. Yasuda, K. Suzuki, K. Tahara, H. Higashi, and S. Era, "Macrophage infiltration and its prognostic implications in breast cancer: the relationship with VEGF expression and microvessel density," Oncology Reports, vol. 14, no. 2, pp. 425431, 2005.

[51] L. Lin, Y.-S. Chen, Y.-D. Yao et al., "CCL18 from tumorassociated macrophages promotes angiogenesis in breast cancer," Oncotarget, vol. 6, no. 33, pp. 34758-34773, 2015.

[52] M. I. Carvalho, I. Pires, M. Dias et al., "Intratumoral CD3+ T-lymphocytes immunoexpression and its association with ckit, angiogenesis, and overall survival in malignant canine mammary tumors," Analytical Cellular Pathology, vol. 2015, Article ID 920409, 8 pages, 2015.

[53] G. E. Lavalle, A. C. Bertagnolli, W. L. F. Tavares, M. A. N. D. Ferreira, and G. D. Cassali, "Mast cells and angiogenesis in canine mammary tumor," Arquivo Brasileiro de Medicina Veterinaria e Zootecnia, vol. 62, no. 6, pp. 1348-1351, 2010.

[54] J. Mucha, K. Majchrzak, B. Taciak, E. Hellmen, and M. Krol, "MDSCs mediate angiogenesis and predispose canine mammary tumor cells for metastasis via IL-28/IL-28RA (IFN- $\lambda$ ) signaling," PLoS ONE, vol. 9, no. 7, Article ID e103249, 2014.

[55] J. Mucha, K. Majchrzak, B. Taciak, E. Hellmén, and M. Król, "MDSCs mediate angiogenesis and predispose canine mammary tumor cells for metastasis via IL-28/IL-28RA (IFN- $\lambda$ ) signaling," PLoS ONE, vol. 9, no. 7, Article ID e103249, 2014.

[56] T. Raposo, H. Gregório, I. Pires, J. Prada, and F. L. Queiroga, "Prognostic value of tumour-associated macrophages in canine mammary tumours," Veterinary and Comparative Oncology, vol. 12, no. 1, pp. 10-19, 2014.

[57] B. C. B. Beirão, T. Raposo, L. Y. Pang, and D. J. Argyle, "Canine mammary cancer cells direct macrophages toward an intermediate activation state between M1/M2," BMC Veterinary Research, vol. 11, article 151, 14 pages, 2015.

[58] M. Król, K. M. Pawłowski, K. Majchrzak, M. Gajewska, A. Majewska, and T. Motyl, "Global gene expression profiles of canine macrophages and canine mammary cancer cells grown as a co-culture in vitro," BMC Veterinary Research, vol. 8, article 16, 2012.

[59] D. Hanahan and R. A. Weinberg, "The hallmarks of cancer," Cell, vol. 100, no. 1, pp. 57-70, 2000.

[60] D. G. DeNardo, J. B. Barreto, P. Andreu et al., "CD4+ T cells regulate pulmonary metastasis of mammary carcinomas by 
enhancing protumor properties of macrophages," Cancer Cell, vol. 16, no. 2, pp. 91-102, 2009.

[61] S. B. Coffelt, K. Kersten, C. W. Doornebal et al., "IL-17producing $\gamma \delta$ T cells and neutrophils conspire to promote breast cancer metastasis," Nature, vol. 522, no. 7556, pp. 345-348, 2015.

[62] G. Giannelli, J. Falk-Marzillier, O. Schiraldi, W. G. StetlerStevenson, and V. Quaranta, "Induction of cell migration by matrix metalloprotease-2 cleavage of laminin-5," Science, vol. 277, no. 5323, pp. 225-228, 1997.

[63] J. Chen, Y. Yao, C. Gong et al., "CCL18 from tumor-associated macrophages promotes breast cancer metastasis via PITPNM3," Cancer Cell, vol. 19, no. 4, pp. 541-555, 2011.

[64] M. Król, K. M. Pawłowski, K. Majchrzak et al., "Density of tumor-associated macrophages (TAMs) and expression of their growth factor receptor MCSF-R and CD14 in canine mammary adenocarcinomas of various grade of malignancy and metastasis," Polish Journal of Veterinary Sciences, vol. 14, no. 1, pp. 3-10, 2011.

[65] A. Estrela-Lima, M. S. S. Araújo, J. M. Da Costa-Neto et al., "Understanding of the immunological heterogeneity of canine mammary carcinomas to provide immunophenotypic features of circulating leukocytes as clinically relevant prognostic biomarkers," Breast Cancer Research and Treatment, vol. 131, no. 3, pp. 751-763, 2012.

[66] A. Estrela-Lima, M. S. S. Araújo, J. M. Costa-Neto et al., "Immunophenotypic features of tumor infiltrating lymphocytes from mammary carcinomas in female dogs associated with prognostic factors and survival rates," BMC Cancer, vol. 10, article no. 256, 2010.

[67] E. P. Chen and E. M. Smyth, "COX-2 and PGE2-dependent immunomodulation in breast cancer," Prostaglandins \& Other Lipid Mediators, vol. 96, no. 1-4, pp. 14-20, 2011.

[68] N. Markosyan, E. P. Chen, V. N. Ndong et al., "Deletion of cyclooxygenase 2 in mouse mammary epithelial cells delays breast cancer onset through augmentation of type 1 immune responses in tumors," Carcinogenesis, vol. 32, no. 10, pp. 14411449, 2011.

[69] M. Ahmadi, D. C. Emery, and D. J. Morgan, "Prevention of both direct and cross-priming of antitumor $\mathrm{CD}^{+} \mathrm{T}$-cell responses following overproduction of prostaglandin $\mathrm{E}_{2}$ by tumor cells in vivo," Cancer Research, vol. 68, no. 18, pp. 7520-7529, 2008.

[70] A. M. Fulton, X. Ma, and N. Kundu, "Targeting prostaglandin E EP receptors to inhibit metastasis," Cancer Research, vol. 66, no. 20, pp. 9794-9797, 2006.

[71] E. Eruslanov, I. Daurkin, J. Ortiz, J. Vieweg, and S. Kusmartsev, "Pivotal advance: tumor-mediated induction of myeloidderived suppressor cells and M2-polarized macrophages by altering intracellular $\mathrm{PGE}_{2}$ catabolism in myeloid cells," Journal of Leukocyte Biology, vol. 88, no. 5, pp. 839-848, 2010.

[72] D. A. Stewart, Y. Yang, L. Makowski, and M. A. Troester, "Basallike breast cancer cells induce phenotypic and genomic changes in macrophages," Molecular Cancer Research, vol. 10, no. 6, pp. 727-738, 2012.

[73] M. I. Carvalho, I. Pires, J. Prada et al., "High COX-2 expression is associated with increased angiogenesis, proliferation and tumoural inflammatory infiltrate in canine malignant mammary tumours: a multivariate survival study," Veterinary and Comparative Oncology, 2016.

[74] P. Vlaicu, P. Mertins, T. Mayr et al., "Monocytes/macrophages support mammary tumor invasivity by co-secreting lineagespecific EGFR ligands and a STAT3 activator," BMC Cancer, vol. 13, article 197, 2013.
[75] S. Goswami, E. Sahai, J. B. Wyckoff et al., "Macrophages promote the invasion of breast carcinoma cells via a colonystimulating factor-1/epidermal growth factor paracrine loop," Cancer Research, vol. 65, no. 12, pp. 5278-5283, 2005.

[76] G. E. Peoples, S. Blotnick, K. Takahashii, M. R. Freeman, M. Klagsbrun, and T. J. Eberlein, "T lymphocytes that infiltrate tumors and atherosclerotic plaques produce heparin-binding epidermal growth factor-like growth factor and basic fibroblast growth factor: a potential pathologic role," Proceedings of the National Academy of Sciences of the United States of America, vol. 92, no. 14, pp. 6547-6551, 1995.

[77] D. M. W. Zaiss, J. van Loosdregt, A. Gorlani et al., "Amphiregulin enhances regulatory $\mathrm{T}$ cell-suppressive function via the epidermal growth factor receptor," Immunity, vol. 38, no. 2, pp. 275-284, 2013.

[78] P. Ray, N. Krishnamoorthy, T. B. Oriss, and A. Ray, "Signaling of c-kit in dendritic cells influences adaptive immunity," Annals of the New York Academy of Sciences, vol. 1183, pp. 104-122, 2010.

[79] T. B. Oriss, N. Krishnamoorthy, P. Ray, and A. Ray, "Dendritic cell c-kit signaling and adaptive immunity: implications for the upper airways," Current Opinion in Allergy and Clinical Immunology, vol. 14, no. 1, pp. 7-12, 2014.

[80] J. Liang, Y.-L. Wu, B.-J. Chen, W. Zhang, Y. Tanaka, and H. Sugiyama, "The C-Kit receptor-mediated signal transduction and tumor-related diseases," International Journal of Biological Sciences, vol. 9, no. 5, pp. 435-443, 2013.

[81] Y. Nishioka, Y. Aono, and S. Sone, "Role of tyrosine kinase inhibitors in tumor immunology," Immunotherapy, vol. 3, no. 1, pp. 107-116, 2011.

[82] H.-Y. Chuang, Y.-F. Chang, R.-S. Liu, and J.-J. Hwang, "Serial low doses of sorafenib enhance therapeutic efficacy of adoptive $\mathrm{T}$ cell therapy in a murine model by improving tumor microenvironment," PLoS ONE, vol. 9, no. 10, Article ID e109992, 2014.

[83] J. Ozao-Choy, M. Ge, J. Kao et al., “The novel role of tyrosine kinase inhibitor in the reversal of immune suppression and modulation of tumor microenvironment for immune-based cancer therapies," Cancer Research, vol. 69, no. 6, pp. 2514-2522, 2009.

[84] B. Thézé, N. Bernards, A. Beynel et al., "Monitoring therapeutic efficacy of sunitinib using $\left[{ }^{18} \mathrm{~F}\right] \mathrm{FDG}$ and $\left[{ }^{18} \mathrm{~F}\right]$ FMISO PET in an immunocompetent model of luminal B (HER2-positive)-type mammary carcinoma," BMC Cancer, vol. 15, article 534, 2015.

[85] C. Brigati, D. M. Noonan, A. Albini, and R. Benelli, "Tumors and inflammatory infiltrates: friends or foes?" Clinical and Experimental Metastasis, vol. 19, no. 3, pp. 247-258, 2002.

[86] F. Balkwill, K. A. Charles, and A. Mantovani, "Smoldering and polarized inflammation in the initiation and promotion of malignant disease," Cancer Cell, vol. 7, no. 3, pp. 211-217, 2005.

[87] J. Condeelis and J. W. Pollard, "Macrophages: obligate partners for tumor cell migration, invasion, and metastasis," Cell, vol. 124, no. 2, pp. 263-266, 2006.

[88] B.-Z. Qian, J. Li, H. Zhang et al., "CCL2 recruits inflammatory monocytes to facilitate breast-tumour metastasis," Nature, vol. 475, no. 7355, pp. 222-225, 2011.

[89] Y. Komohara, M. Jinushi, and M. Takeya, "Clinical significance of macrophage heterogeneity in human malignant tumors," Cancer Science, vol. 105, no. 1, pp. 1-8, 2014.

[90] R. Ward, A. H. Sims, A. Lee et al., "Monocytes and macrophages, implications for breast cancer migration and stem cell-like activity and treatment," Oncotarget, vol. 6, no. 16, pp. 1468714699, 2015. 
[91] E. Y. Lin, A. V. Nguyen, R. G. Russell, and J. W. Pollard, "Colonystimulating factor 1 promotes progression of mammary tumors to malignancy," The Journal of Experimental Medicine, vol. 193, no. 6, pp. 727-740, 2001.

[92] J. B. Wyckoff, Y. Wang, E. Y. Lin et al., "Direct visualization of macrophage-assisted tumor cell intravasation in mammary tumors," Cancer Research, vol. 67, no. 6, pp. 2649-2656, 2007.

[93] D. Ishihara, A. Dovas, L. Hernandez et al., "Wiskott-Aldrich syndrome protein regulates leukocyte-dependent breast cancer metastasis," Cell Reports, vol. 4, no. 3, pp. 429-436, 2013.

[94] K. D. Simpson, D. J. Templeton, and J. V. Cross, "Macrophage migration inhibitory factor promotes tumor growth and metastasis by inducing myeloid-derived suppressor cells in the tumor microenvironment," Journal of Immunology, vol. 189, no. 12, pp. 5533-5540, 2012.

[95] M. Król, K. M. Pawłowski, K. Majchrzak, M. Gajewska, A. Majewska, and T. Motyl, "Global gene expression profiles of canine macrophages and canine mammary cancer cells grown as a co-culture in vitro," BMC Veterinary Research, vol. 8 , article 16, pp. 1-20, 2012.

[96] M. Nowak, J. P. Madej, J. Rossowska, and J. A. Madej, "Involvement of CD8+ cells in protective mechanisms in canine mammary adenocarcinomas," Bulletin of the Veterinary Institute in Pulawy, vol. 51, no. 3, pp. 445-448, 2007.

[97] E. M. Smyth, T. Grosser, M. Wang, Y. Yu, and G. A. FitzGerald, "Prostanoids in health and disease," Journal of Lipid Research, vol. 50, supplement, pp. S423-S428, 2009.

[98] M. Doré, "Cyclooxygenase-2 expression in animal cancers," Veterinary Pathology, vol. 48, no. 1, pp. 254-265, 2011.

[99] F. L. Queiroga, I. Pires, L. Lobo, and C. S. Lopes, “The role of Cox-2 expression in the prognosis of dogs with malignant mammary tumours," Research in Veterinary Science, vol. 88, no. 3, pp. 441-445, 2010.

[100] B.-W. Park, S. Park, H. S. Park et al., "Cyclooxygenase-2 expression in proliferative Ki-67-positive breast cancers is associated with poor outcomes," Breast Cancer Research and Treatment, vol. 133, no. 2, pp. 741-751, 2012.

[101] F. Millanta, P. Asproni, A. Canale, S. Citi, and A. Poli, "COX-2, mPGES-1 and EP2 receptor immunohistochemical expression in canine and feline malignant mammary tumours," Veterinary and Comparative Oncology, vol. 3, pp. 270-280, 2014.

[102] A. Greenhough, H. J. M. Smartt, A. E. Moore et al., "The COX2/PGE2 pathway: key roles in the hallmarks of cancer and adaptation to the tumour microenvironment," Carcinogenesis, vol. 30, no. 3, pp. 377-386, 2009.

[103] F. Hoellen, K. Kelling, C. Dittmer, K. Diedrich, M. Friedrich, and M. Thill, "Impact of cyclooxygenase-2 in breast cancer," Anticancer Research, vol. 31, no. 12, pp. 4359-4367, 2011.

[104] N. Markosyan, E. P. Chen, and E. M. Smyth, "Targeting COX-2 abrogates mammary tumorigenesis," OncoImmunology, vol. 3, no. 6, Article ID e29287, 2014.

[105] Y.-R. Na, Y.-N. Yoon, D.-I. Son, and S.-H. Seok, "Cyclooxygenase-2 inhibition blocks M2 macrophage differentiation and suppresses metastasis in murine breast cancer model," PLoS ONE, vol. 8, no. 5, Article ID e63451, 2013.

[106] N. Markosyan, E. P. Chen, R. A. Evans, V. Ndong, R. H. Vonderheide, and E. M. Smyth, "Mammary carcinoma cell derived cyclooxygenase 2 suppresses tumor immune surveillance by enhancing intratumoral immune checkpoint activity," Breast Cancer Research, vol. 15, no. 5, article no. R75, 2013.
[107] B. A. Pockaj, G. D. Basu, L. B. Pathangey et al., "Reduced Tcell and dendritic cell function is related to cyclooxygenase-2 overexpression and prostaglandin $\mathrm{E}_{2}$ secretion in patients with breast cancer," Annals of Surgical Oncology, vol. 11, no. 3, pp. 328-339, 2004.

[108] C. Nataraj, D. W. Thomas, S. L. Tilley et al., "Receptors for prostaglandin $\mathrm{E}_{2}$ that regulate cellular immune responses in the mouse," Journal of Clinical Investigation, vol. 108, no. 8, pp. 12291235, 2001.

[109] C. Yao, D. Sakata, Y. Esaki et al., "Prostaglandin E2-EP4 signaling promotes immune inflammation through TH1 cell differentiation and TH17 cell expansion," Nature Medicine, vol. 15, no. 6, pp. 633-640, 2009.

[110] S. G. Harris, J. Padilla, L. Koumas, D. Ray, and R. P. Phipps, "Prostaglandins as modulators of immunity," Trends in Immunology, vol. 23, no. 3, pp. 144-150, 2002.

[111] R. P. Phipps, S. H. Stein, and R. L. Roper, "A new view of prostaglandin E regulation of the immune response," Immunology Today, vol. 12, no. 10, pp. 349-352, 1991.

[112] S. Sharma, M. Stolina, S.-C. Yang et al., "Tumor cyclooxygenase 2-dependent suppression of dendritic cell function," Clinical Cancer Research, vol. 9, no. 3, pp. 961-968, 2003.

[113] P. Kaliński, C. M. U. Hilkens, A. Snijders, F. G. M. Snijdewint, and M. L. Kapsenberg, "Dendritic cells, obtained from peripheral blood precursors in the presence of PGE2, promote Th2 responses," Advances in Experimental Medicine and Biology, vol. 417, pp. 363-367, 1997.

[114] M. Sahin, E. Sahin, and S. Koksoy, "Regulatory T cells in cancer: an overview and perspectives on cyclooxygenase- 2 and Foxp3 DNA methylation," Human Immunology, vol. 74, no. 9, pp. 10611068, 2013.

[115] M. Mahic, S. Yaqub, C. C. Johansson, K. Taskén, and E. M. Aandahl, "FOXP3 ${ }^{+} \mathrm{CD} 4{ }^{+} \mathrm{CD} 25^{+}$adaptive regulatory $\mathrm{T}$ cells express cyclooxygenase- 2 and suppress effector $\mathrm{T}$ cells by a prostaglandin $\mathrm{E}_{2}$-dependent mechanism," Journal of Immunology, vol. 177, no. 1, pp. 246-254, 2006.

[116] F. Baratelli, Y. Lin, L. Zhu et al., "Prostaglandin $E_{2}$ induces FOXP3 gene expression and $\mathrm{T}$ regulatory cell function in human $\mathrm{CD}^{+} \mathrm{T}$ cells," The Journal of Immunology, vol. 175, no. 3, pp. 1483-1490, 2005.

[117] S. Yaqub, K. Henjum, M. Mahic et al., "Regulatory T cells in colorectal cancer patients suppress anti-tumor immune activity in a COX-2 dependent manner," Cancer Immunology, Immunotherapy, vol. 57, no. 6, pp. 813-821, 2008.

[118] J. Yokokawa, V. Cereda, C. Remondo et al., "Enhanced functionality of $\mathrm{CD}^{+} \mathrm{CD} 25^{\text {high }} \mathrm{FoxP}^{+}$regulatory $\mathrm{T}$ cells in the peripheral blood of patients with prostate cancer," Clinical Cancer Research, vol. 14, no. 4, pp. 1032-1040, 2008.

[119] X.-L. Yuan, L. Chen, M.-X. Li et al., "Elevated expression of Foxp3 in tumor-infiltrating Treg cells suppresses T-cell proliferation and contributes to gastric cancer progression in a COX-2-dependent manner," Clinical Immunology, vol. 134, no. 3, pp. 277-288, 2010.

[120] E. Kadioglu and M. De Palma, "Cancer metastasis: perivascular macrophages under watch," Cancer Discovery, vol. 5, no. 9, pp. 906-908, 2015.

[121] B. C. B. Beirão, T. Raposo, L. Y. Pang, and D. J. Argyle, "Canine mammary cancer cells direct macrophages toward an intermediate activation state between M1/M2," BMC Veterinary Research, vol. 11, article no. 151, 2015.

[122] Z. Hou, D. J. Falcone, K. Subbaramaiah, and A. J. Dannenberg, "Macrophages induce COX-2 expression in breast cancer cells: 
role of IL-1beta autoamplification," Carcinogenesis, vol. 32, no. 5, pp. 695-702, 2011.

[123] M. J. Guimarães, M. I. Carvalho, I. Pires et al., "Concurrent expression of cyclo-oxygenase-2 and epidermal growth factor receptor in canine malignant mammary tumours," Journal of Comparative Pathology, vol. 150, no. 1, pp. 27-34, 2014.

[124] A. M. Xu and P. H. Huang, "Receptor tyrosine kinase coactivation networks in cancer," Cancer Research, vol. 70, no. 10, pp. 3857-3860, 2010.

[125] J. Singer, J. Fazekas, W. Wang et al., "Generation of a canine antiEGFR (ErbB-1) antibody for passive immunotherapy in dog cancer patients," Molecular Cancer Therapeutics, vol. 13, no. 7, pp. 1777-1790, 2014.

[126] J. Singer, M. Weichselbaumer, T. Stockner et al., "Comparative oncology: ErbB-1 and ErbB-2 homologues in canine cancer are susceptible to cetuximab and trastuzumab targeting," Molecular Immunology, vol. 50, no. 4, pp. 200-209, 2012.

[127] S. R. Hubbard and W. T. Miller, "Receptor tyrosine kinases: mechanisms of activation and signaling," Current Opinion in Cell Biology, vol. 19, no. 2, pp. 117-123, 2007.

[128] P. Blume-Jensen and T. Hunter, "Oncogenic kinase signalling," Nature, vol. 411, no. 6835, pp. 355-365, 2001.

[129] M. K. Paul and A. K. Mukhopadhyay, "Tyrosine kinase-role and significance in Cancer," International Journal of Medical Sciences, vol. 1, pp. 101-115, 2004.

[130] A. Bennasroune, A. Gardin, D. Aunis, G. Crémel, and P. Hubert, "Tyrosine kinase receptors as attractive targets of cancer therapy," Critical Reviews in Oncology/Hematology, vol. 50, no. 1, pp. 23-38, 2004.

[131] M. A. Lemmon and J. Schlessinger, "Cell signaling by receptor tyrosine kinases," Cell, vol. 141, no. 7, pp. 1117-1134, 2010.

[132] J. S. Biscardi, R. C. Ishizawar, C. M. Silva, and S. J. Parsons, "Tyrosine kinase signalling in breast cancer: epidermal growth factor receptor and c-Src interactions in breast cancer," Breast Cancer Research, vol. 2, no. 3, pp. 203-210, 2000.

[133] H. Tsuda, D. Morita, M. Kimura et al., "Correlation of KIT and EGFR overexpression with invasive ductal breast carcinoma of the solid-tubular subtype, nuclear grade 3 , and mesenchymal or myoepithelial differentiation," Cancer Science, vol. 96, no. 1, pp. 48-53, 2005.

[134] B. Huang, Z. Lei, G.-M. Zhang et al., "SCF-mediated mast cell infiltration and activation exacerbate the inflammation and immunosuppression in tumor microenvironment," Blood, vol. 112, no. 4, pp. 1269-1279, 2008.

[135] J. Ursini-Siegel, "Can pharmacological receptor tyrosine kinase inhibitors sensitize poor outcome breast tumors to immunebased therapies?" Frontiers in Oncology, vol. 3, article 23, 2013.

[136] G. Singh-Ranger, M. Salhab, and K. Mokbel, "The role of cyclooxygenase-2 in breast cancer: review," Breast Cancer Research and Treatment, vol. 109, no. 2, pp. 189-198, 2008.

[137] R. M. Srivastava, S. C. Lee, P. A. A. Filho et al., "Cetuximabactivated natural killer and dendritic cells collaborate to trigger tumor antigen-specific T-cell immunity in head and neck cancer patients," Clinical Cancer Research, vol. 19, no. 7, pp.18581872, 2013.

[138] S. Park, Z. Jiang, E. D. Mortenson et al., "The therapeutic effect of anti-HER2/neu antibody depends on both innate and adaptive immunity," Cancer Cell, vol. 18, no. 2, pp. 160-170, 2010.

[139] S. Ladoire, L. Arnould, G. Mignot et al., "T-bet expression in intratumoral lymphoid structures after neoadjuvant trastuzumab plus docetaxel for HER2-overexpressing breast carcinoma predicts survival," British Journal of Cancer, vol. 105, no. 3, pp. 366-371, 2011.

[140] X. Yang, X. Zhang, E. D. Mortenson, O. Radkevich-Brown, Y. Wang, and Y.-X. Fu, "Cetuximab-mediated tumor regression depends on innate and adaptive immune responses," Molecular Therapy, vol. 21, no. 1, pp. 91-100, 2013.

[141] J. Wyckoff, W. Wang, E. Y. Lin et al., "A paracrine loop between tumor cells and macrophages is required for tumor cell migration in mammary tumors," Cancer Research, vol. 64, no. 19, pp. 7022-7029, 2004.

[142] F. Abe, I. Younos, S. Westphal et al., "Therapeutic activity of sunitinib for Her2/neu induced mammary cancer in FVB mice," International Immunopharmacology, vol. 10, no. 1, pp. 140-145, 2010.

[143] T. P. Raposo, B. C. B. Beirão, L. Y. Pang, F. L. Queiroga, and D. J. Argyle, "Inflammation and cancer: till death tears them apart," Veterinary Journal, vol. 205, no. 2, pp. 161-174, 2015.

[144] A. Ben-Baruch, "Host microenvironment in breast cancer development. Inflammatory cells, cytokines and chemokines in breast cancer progression: reciprocal tumor-microenvironment interactions," Breast Cancer Research, vol. 5, no. 1, pp. 31-36, 2003. 


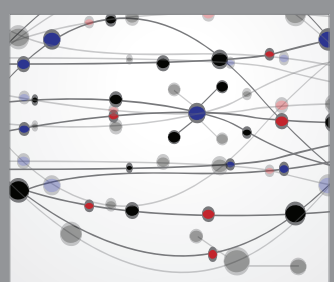

The Scientific World Journal
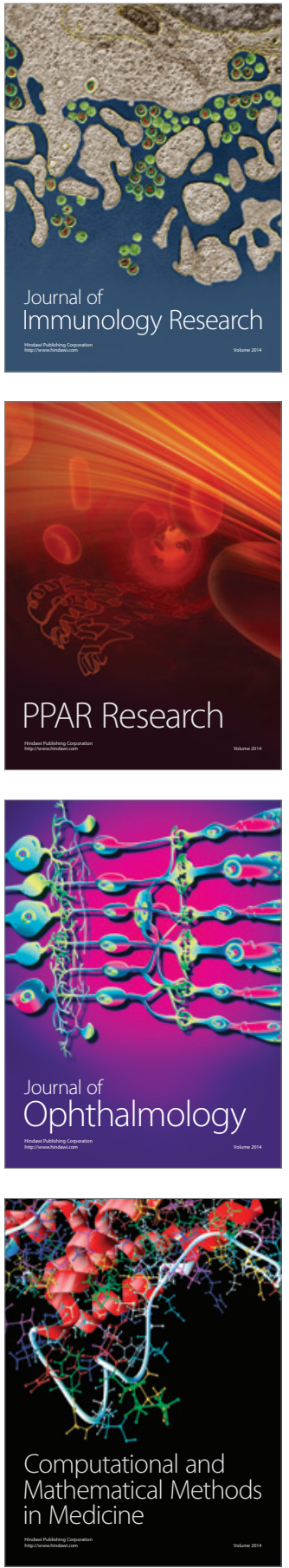

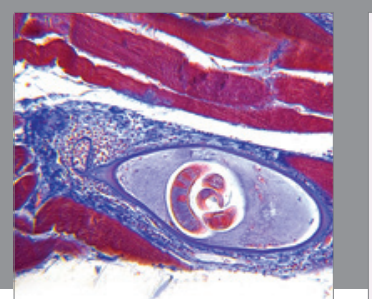

Gastroenterology Research and Practice

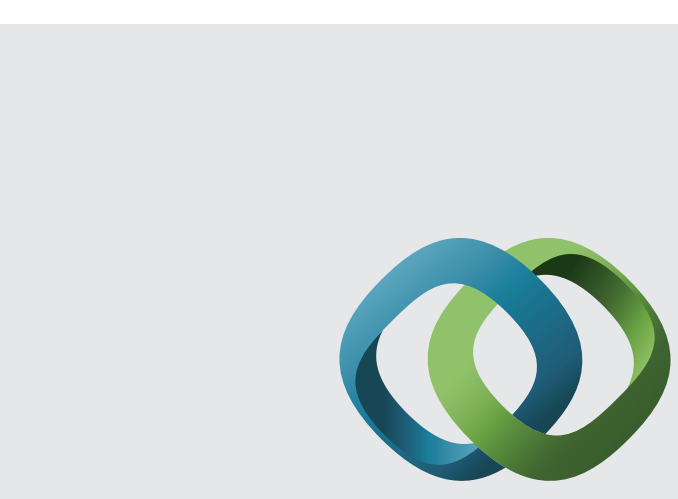

\section{Hindawi}

Submit your manuscripts at

http://www.hindawi.com
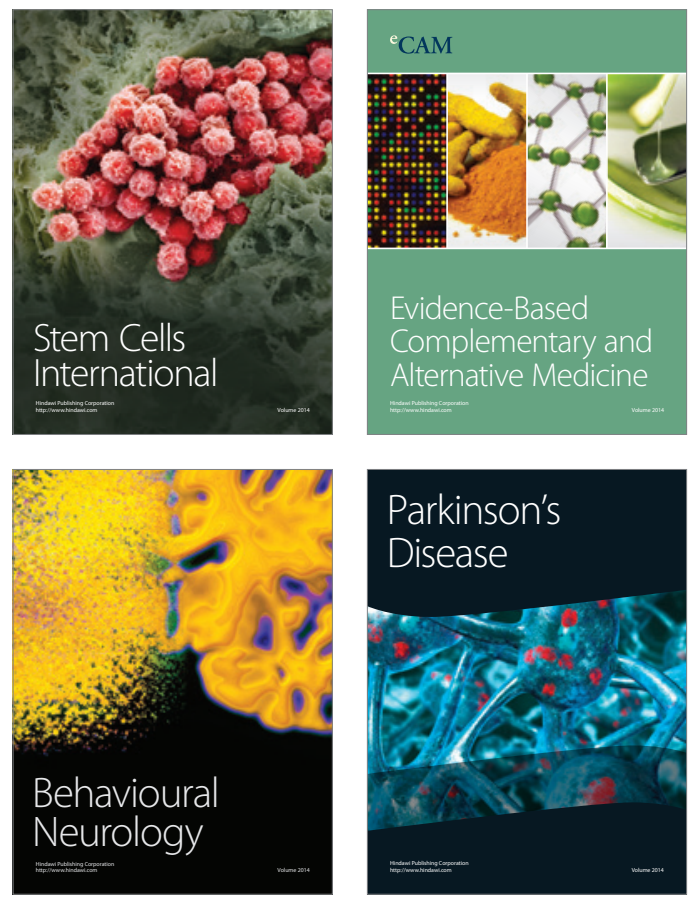
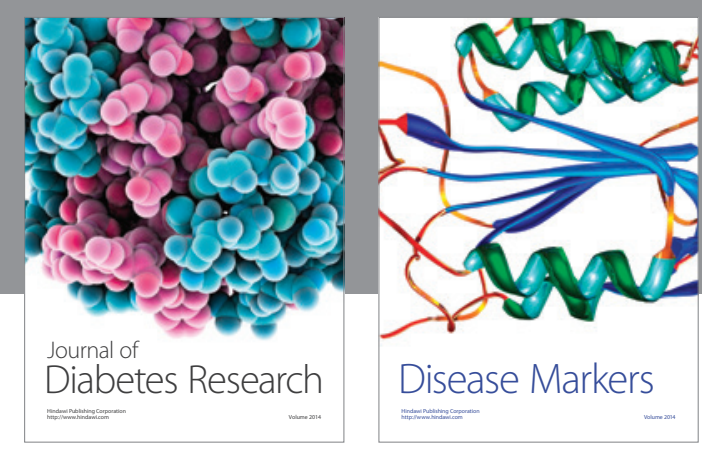

Disease Markers
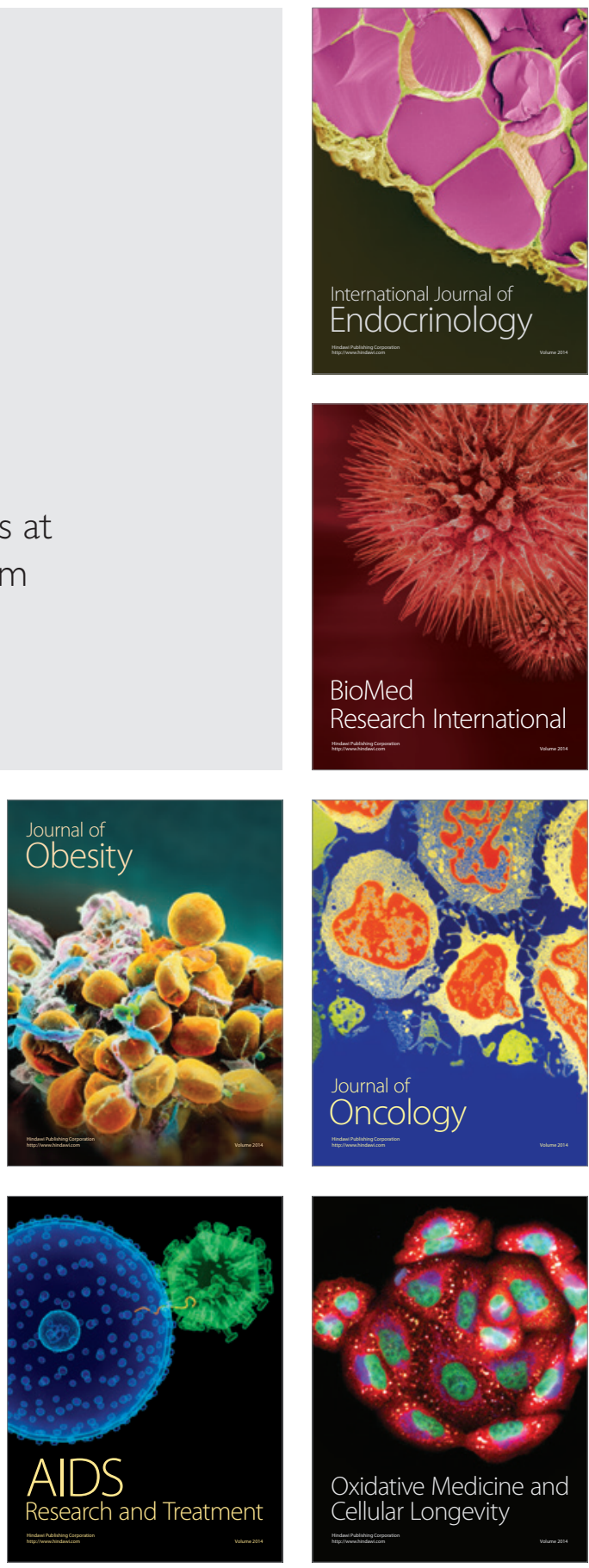